\title{
Frequency of Positive PCR test and Complications in Nasopharyngeal Swabs of Suspected Patients and Contacts of COVID-19 Tested at Allied Hospital Faisalabad
}

\author{
Muhammad Saeed', Summak Saeed ${ }^{2}$, Asma Tariq ${ }^{3}$, Hafiz Sajjad Hyder ${ }^{4}$
}

\author{
1 Professor, Department of ENT, Allied Hospital/Faisalabad Medical University, Faisalabad Pakistan \\ 1 Manuscript writing \\ 2 House Officer, Allied Hospital, Faisalabad Pakistan \\ 2 Data collection \\ 3 Women Medical Officer, DHQ Hospital, Faisalabad Pakistan \\ 3 Literature review, References writing \\ 4 Assistant Professor, Department of ENT, Allied Hospital/Faisalabad Medical University, Faisalabad Pakistan \\ 4 Statistical analysis
}

CORRESPONDING AUTHOR

Dr. Muhammad Saeed

Professor, Department of ENT, Allied Hospital /

Faisalabad Medical University, Faisalabad Pakistan

Email: saeedent@ymail.com

Submitted for Publication: 16-12-2020 Accepted for Publication 02-01-2021

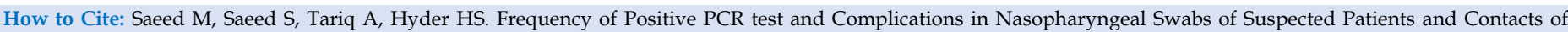
COVID-19 Tested at Allied Hospital Faisalabad. APMC 2021;15(1):25-7. DOI: 10.29054/APMC/2021.1118

\section{ABSTRACT}

Background: COVID-19 is a severe respiratory disease, started in China. For diagnosis, we need swabs from different regions of respiratory tract. Nasopharyngeal swab is the preferred method. Rt-PCR for Corona virus is the gold standard lab test for diagnosis. Objective: To determine frequency of positive PCR tests and complications in total number of nasopharyngeal samples taken at ENT department of Allied Hospital, Faisalabad Pakistan. Study Design: Descriptive cross-sectional study. Settings: ENT department, Allied Hospital, Faisalabad Pakistan. Duration: $1^{\text {st }}$ May 2020 to $31^{\text {st }}$ August 2020. Methodology: Nasopharyngeal swabs of suspected cases, their contacts, and healthcare workers were taken at ENT department of Allied Hospital. All samples were sent to BSL-LAB. The complication related to procedure were also noted. The result was labelled as detected and non-detected. Results: Total sample taken were 2909 out of which 627 (22\%) cases were positive for Corona virus while $2282(78 \%)$ were negative. Pain was most frequent complication (68\%) followed by blood staining of swab (31\%) and epistaxis (1\%). Conclusion: Frequency of positive corona virus case presenting to allied Hospital is $22 \%$. Nasopharyngeal swabs are a safe and effective method of sampling in suspected Corona Virus cases. Pain during the procedure is the most frequent complication.

Keywords: Positive PCR test, Nasopharyngeal Swabs, COVID-19.

\section{INTRODUCTION}

Severe acute respiratory syndrome corona virus 2 commonly known as COVID-19 is a severe respiratory disease and its outbreak was started in Wuhan, Hubei Province of China. After it starts from China, it spreads to almost all parts of the world e.g. Italy, Spain, Brazil, India, Pakistan etc. it was declared as global emergency on $30^{\text {th }}$ January,2020 by WHO and a global pandemic on 11 March 2020. ${ }^{1}$

COVID-19 is a disease that spreads through droplet infection from humans to humans. After its entry into the human body, the virus starts the process of replication in upper respiratory tract and a symptom complex starts that include fever, sore throat, myalgia, fatigue. the severity of symptoms varies from asymptomatic to mild to severe and critical. ${ }^{2}$ In the lower respiratory tract, ACEII receptors act as a binding site for virus and leads to severe respiratory tract symptoms. The ACE-II receptors are also present in GIT, heart, kidney. ${ }^{3}$ So, it leads to variety of symptoms in these regions e.g. gastroenteritis, pain abdomen etc.
To diagnose a case of COVID-19, we need sampling that are either obtained from upper or lower respiratory tract. The sampling types include nasopharyngeal swabs, oropharyngeal swabs, nasal swabs, sputum, bronchoalveolar lavage. However, the most commonly used sampling procedure is nasopharyngeal swab an it has high sensitivity and specificity $(80-90 \%)$ and it is relatively easy. ${ }^{4}$

COVID-19 cases started in Pakistan in late February. Soon it started spreading throughout the country. So, the health authorities established a number of quarantine centers and corona units in different hospitals, throughout the country. Allied hospital Faisalabad was among those hospitals receiving corona virus patients. Different departments of Allied Hospital were converted to corona units for receiving and treating COVID-19 patients. Soon health care workers also started contracting corona virus.

ENT department of Allied Hospital was assigned the duty of taking sampling from suspected cases of COVID19, their contacts and health care workers. 
Nasopharyngeal sampling method was employed to take samples from all these persons and samples were sent to laboratory for detection of corona virus through PCR. In this study we have find out the frequency of positive PCR tests in total number of samples taken between $1^{\text {st }}$ May 2020 to 31 ${ }^{\text {st }}$ August 2020.

\section{METHODOLOGY}

Study Design: Descriptive cross-sectional study. Settings: ENT Department, Allied Hospital, Faisalabad. Duration: 4 months from $1^{\text {st }}$ May to 30th August 2020.

Sample Technique: Non probability consecutive sampling.

Sample Size: 2909 samples.

Inclusion Criteria: 1. All suspected cases of corona virus presenting to Allied hospital. 2. Contacts of cases of corona virus presenting to Allied hospital. 3. Health care workers of Allied Hospital and their family members with symptoms of corona virus infection.

Exclusion Criteria: Samples taken from other than Allied Hospital, Faisalabad.

Data Collection Procedure: All the suspected cases, their contacts, and healthcare workers with COVID-19 symptoms presenting to ENT Department for sampling were included in the study. their names, father name, CNIC number, address and phone number were noted. each person was assigned a specific Laboratory number. Nasopharyngeal swabs of all persons were obtained. Complaints of pain, staining of nasal swab, epistaxis and suspected perforation of cribriform plate were noted. all the samples were sent to BSL-LAB of Allied Hospital at proper temperature and in specific container. rt-PCR of all these samples were performed at BSL-LAB of Allied Hospital and were reported as, Detected, (positive) and, non-detected, (negative)

Data Analyzing Procedure: All the data was presented in the form of tables and pie charts. Excel 2016 was used to analyze and draw the results and percentage of different variables.

\section{RESULTS}

Total sample taken were 2909 out of which 627 (22\%) cases were positive for Corona virus while 2282 (78\%) were negative. Table 1

Figure 1: Incidence of COVID-19 in Corona patients $(\mathrm{n}=2909)$

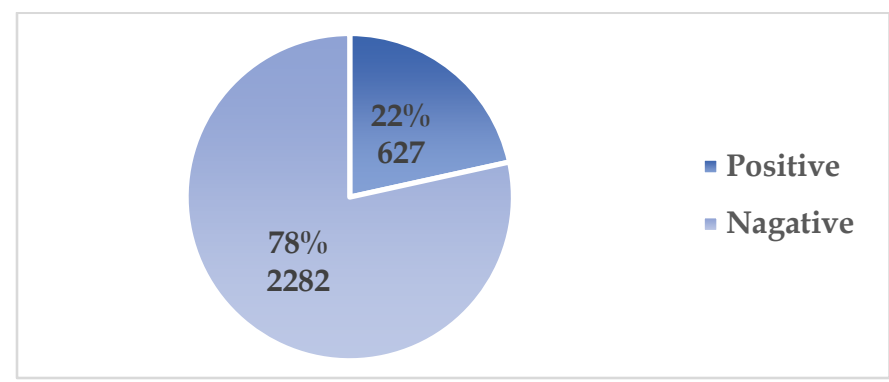

Pain was most frequent complication $(68 \%)$ followed by blood staining of swab (31\%) and epistaxis $(1 \%)$. Table 2

Figure 2: Complications of nasopharyngeal swab $(\mathrm{n}=2909)$

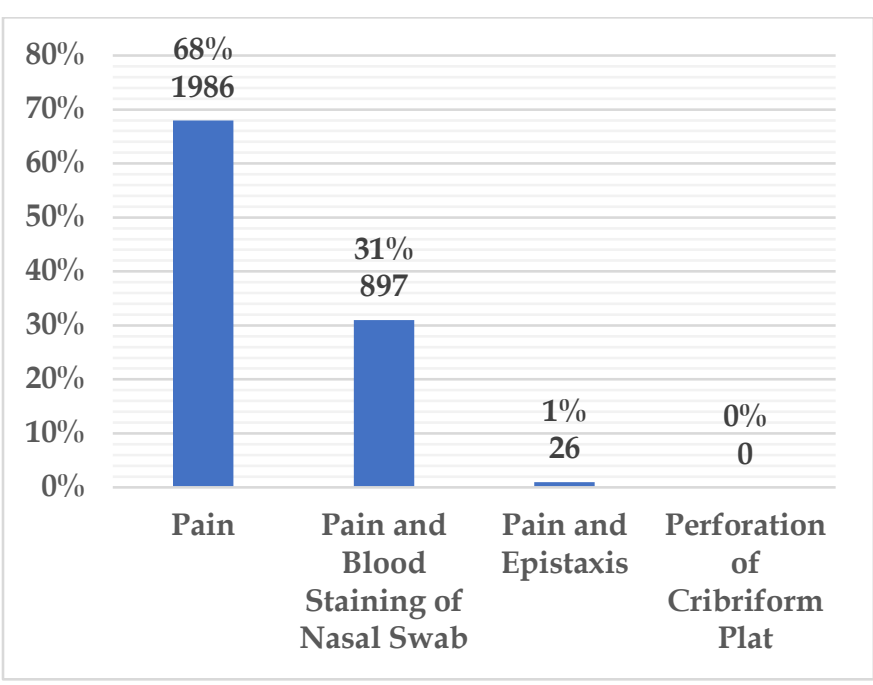

\section{DISCUSSION}

Throughout the world, real time reverse transcription PCR based viral nucleic acid test is being used to screen and confirm patient suffering from corona virus due to its high efficacy, and quick results. ${ }^{5}$ The SARS-CoV-2 virus actively replicate in upper respiratory tract. This factor is proven by the observation that viral particles were higher in upper respiratory tract even during the first week of illness and peaked on 4 to 6 days. The amount of virus in upper respiratory tract secretions ranges from $10^{4}$ to $10^{7}$ copies per $\mathrm{ml} .^{6}$

The nose and mouth are the two sites that can be used to take samples for PCR. The nose leads to the nasopharynx and mouth leads to oropharynx. A good knowledge of the anatomy and structure of these sites is necessary to take precise and adequate samples and also reduce complications and pain to the patients. ${ }^{7}$ The nasopharynx is located posteriorly the nasal cavities and approximate distance from nares to nasopharynx is $10-12 \mathrm{~cm} .{ }^{8}$ Sampling from oropharynx requires the doctor to directly inspect the oropharynx of patient and also can cause coughing while sampling from nasopharynx can lead to epistaxis and also coughing. So, the person taking samples should have good skills and also should wear proper personal protective equipment. ${ }^{9}$

In Allied hospital Faisalabad, we used nasopharyngeal rout of sampling. Post graduate residents of ENT were deputed to take samples as they are familiar to anatomy of nose and nasopharynx. A separate sampling room was established. The residents were provided with full PPEs. All samples were properly saved and sent to BCL-LAB of Allied Hospital Faisalabad. The results were communicated to suspected persons and relevant health authority. 
A total 2909 sample were taken between $1^{\text {st }}$ May to $30^{\text {th }}$ August by ENT department. Out of which 627 persons were proved to be positive while 2282 persons were negative. So, the positive percentage $22 \%$ and negative percentage was $78 \%$.

$1986(68 \%)$ patients only felt pain while taking samples.in $897(31 \%)$ patients there was blood staining of swabs along with pain while in $26(1 \%)$ patients there was epistaxis along with pain. No case of perforation of cribriform plate was noted.

So, in our department pain (discomfort to severe) during introduction of swab into nasopharynx was most frequent complication and experienced by all patients followed by Staining of swabs and epistaxis.

\section{CONCLUSION}

We concluded our study with finding that $22 \%$ of Patient were positive for Corona Virus PCR out of total sample. Also, Nasopharyngeal swabs are safe and effective method for detection of Corona Virus.

\section{LIMITATIONS}

Sampling for detection of Corona virus was carried out on large scale throughout Faisalabad. But we have only included the sampling done at Allied Hospital Faisalabad.

\section{SUGGESTIONS / RECOMMENDATIONS}

Studies on other easier methods should be done e.g., samples form mouth gargles, sputum.
CONFLICT OF INTEREST / DISCLOSURE

There was no conflict of interest.

\section{ACKNOWLEDGEMENTS}

We acknowledge hospital administration for provision of the equipment and help in retrieval of the data.

\section{REFERENCES}

1. Coronavirus diseas (COVID-19)- events as they happen. https://www.who.int/emergencies/diseases/novel-coronavirus2019/events-as-they-happen

2. Li Q, Guan X, Wu P, Wang X, Zhou L, Tong Y, et al. Early transmission dynamics in Wuhan, China, of Novel Coronavirusinfected pneumonia. N Engl J Med. 2020;382(13):1199-207.

3. Patel AB, Verma A. COVID-19 and Angiotensin-Converting Enzyme Inhibitors and Angiotensin Receptor Blockers: What Is the Evidence? JAMA. 2020;323(18):1769-70.

4. Guidelines 2019 Novel Coronavirus (2019 nCoV) Management In Malaysia. https://mpaeds.my/wpcontent/uploads/2020/01/Guidelines-2019-Novel-Coronavirus2019-nCoV-Management-In-Malaysia-No.-22020.pdf

5. Liu R, Han H, Liu F, Lv Z, Wu K, Liu Y, et al. Positive rate of RTPCR detection of SARS-CoV-2 infection in 4880 cases from one hospital in Wuhan, China, from Jan to Feb 2020. Clin Chim Acta. 2020;505:172-5.

6. Pan Y, Zhang D, Yang P, Poon LLM, Wang Q. Viral load of SARSCoV-2 in clinical samples. Lancet Infect Dis. 2020;20(4):411-2.

7. Wrobel BB, Leopold DA. Olfactory and sensory attributes of the nose. Otolaryngol Clin North Am. 2005;38(6):1163-70.

8. Johnson M, Miskovic A, Ray S, Chong K, Hickson M, Bingham B, et al. The nasopharyngeal airway: Estimation of the nares-tomandible and nares-to-tragus distance in young children to assess current clinical practice. Resuscitation. 2019;140:50-4.

9. Tu YP, Jennings R, Hart B, Cangelosi GA, Wood RC, Wehber K, et al. Swabs Collected by Patients or Health Care Workers for SARSCoV-2 Testing. N Engl J Med. 2020;383(5):494-6. 